\title{
Teatro en Buenos Aires, julio-agosto 2007
}

\section{Nora Glickman}

La temporada teatral de este invierno en Buenos Aires sobresale por su creciente número de espectáculos (más de trescientos durante los fines de semana, aunque también se dan funciones esparcidas durante el resto de la semana). Parece incontenible la necesidad de hacer teatro de autores nacionales y extranjeros, tanto traducciones originales como adaptaciones, y de hacerlo en todas partes; en espacios oficiales y alternativos; en salas grandes y pequeñas; en clubes, salones familiares, casonas, garages, y aún en foros familiares íntimos, exclusivos y populares. Durante las dos semanas que pasé en Buenos Aires traté de abarcar cuanto me fue posible, sabiendo que mucho más quedaba por ver en una próxima visita:

Fetiche, de José María Muscari (teatro Sarmiento, del Complejo Teatral de Buenos Aires), calificada como un "biodrama," está inspirada en una persona real, ficcionalizada. Seis mujeres representan seis versiones de una misma persona, Cristina, durante distintas etapas de su vida, de los veinte a los ochenta años. La obra toma lugar en un gimnasio de mujeres en el que se cuestionan la sexualidad, el deporte, las dietas y el ejercicio del culturalismo físico. Allí las mujeres, que incluyen un travesti, comparten filosóficamente sus confesiones sobre la soledad a la que cada una se ve relegada, pero al mismo tiempo buscan en el deporte una salida positiva a su ensimismamiento. La obra es frenética, dinámica... y extenuante para el espectador, dados los alardes de destreza muscular de parte de las actrices y las pesas que levantan. Varias pantallas de televisión complementan simultáneamente al espectáculo, exhibiendo los resultados de las proezas en las carnes tensas y lubricadas de las mujeres, y finalmente en el propio sujeto del biodrama, un travesti.

Espía a una mujer que se mata (El Camarín de las Musas), es una versión libre de El tío Vania de Antón Chejov. La adaptación de Daniel Veronese - con variantes de actoriales provenientes de Stanislavsky y de 


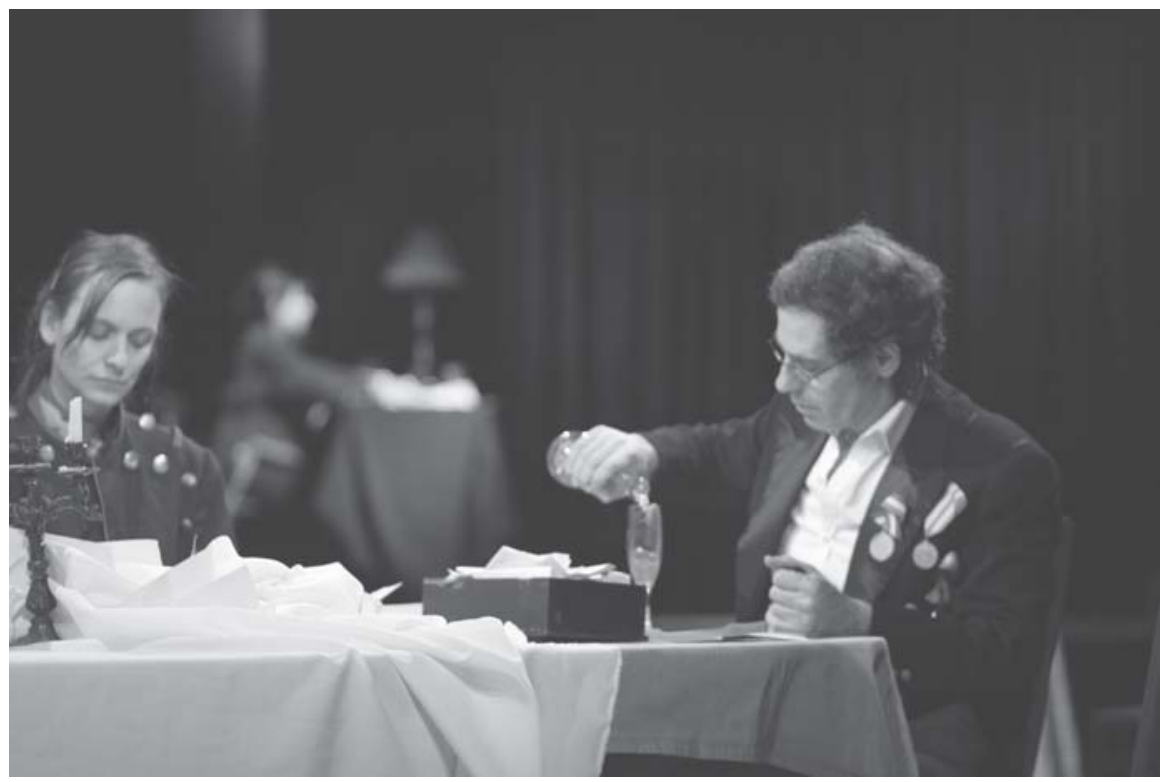

Español para extranjeros. Foto de: Guillermo Monteleone.

Genet - se expresa en una puesta minimalista, casi desprovista de vestuario y de moblaje, que trata de evocar el ambiente campestre de la época zarista. La representación de Veronese es ilustrativa de su concepción teatral, más violenta e histérica que la sugerida por Chejov. Como en la versión original, se cuestionan aquí la búsqueda de Dios, del amor y de la verdad, la fragilidad de las promesas artísticas, las distancias sociales, las relaciones generacionales y las conyugales. Como en Chejov, la resignación y el desaliento siguen siendo las constantes que dominan la escena.

Espectáculos unipersonales, tal vez por el bajo costo de la producción, abundan en la capital bonaernse: A las múltiples e increíbles variedades de tango se añade "Hava Naguila Tango Bar" (Teatro Gargantúa) concebido e interpretado creativamente por Alejandra Wila, bajo la dirección de Irene Rotenberg, en una dinámica combinación de tangos con valses, jazz y música judía.

En ALGO sobre mi madre.(TODO sería demasiado) (La Casona del Teatro) se explaya la virtud actoral y gestual de Gabriela Acher, con un impecable sentido del tiempo para hacer llegar su humor a público de aficionados a su arte, y muy dispuestos a aplaudirlo. Ya sea en chistes o quejas, prima un sentido de humor judío centrado en la maternidad de toda 
etnia, aunque la "ídishe mame" se distingue por su dosis de leve reproche envuelto en culpabilidad: "Mi hijo es perfecto, pero yo lo puedo mejorar. Si no.... ¿para qué estoy?' El show de Acher recuerda al exitoso Jackie Mason de Broadway.

El elenco del programa de Open House de Daniel Veronese (El Callejón), se compone de diez actores, tres de los cuales aparecen en el programa con su nombre tachado. Explica uno de los actores en un tono coloquial, que pretende conversar llanamente con el público y no actuar para él, que

sabemos que Open House es una obra que no dejaremos de hacer nunca. No depende del público. Si el público no viene la haremos igual. Nosotros sabemos y podemos soportar las pérdidas y el abandono. Si uno de nosotros decide irse de la obra, la obra continúa; durante cuatro años estuvo con nosotros Andy - Andy era nuestro conejo - y hoy ya no está. Murió. Ahora nos abandonó el chico del bigote, pero en Open House no hay posibilidad de ser reemplazado, la propia obra se hace cargo de la pérdida. Así, Open House irá desapareciendo de a poco, hasta que sólo queden las huellas de las palabras. Miramos para adelante. ¿Qué hay? ¿En qué nos

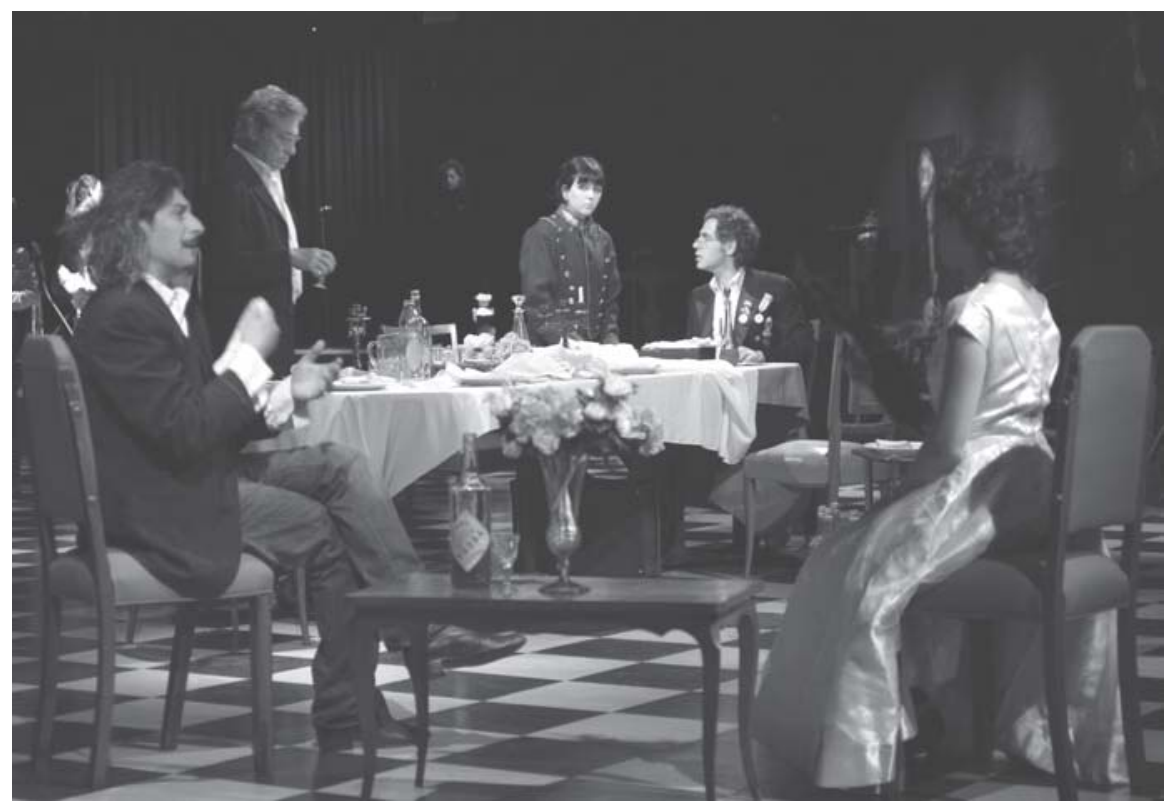

Español para extranjeros. Foto de: Guillermo Monteleone. 
transformaremos? No lo sabemos. Sólo sabemos que la obra tendrá una muerte natural. Esto es Open House.

El niño argentino (Teatro Regina) de Mauricio Kartún, es a juicio de la crítica, al cual me adhiero sin reserva, la obra de mayor alcance en la escena porteña actual. A partir de la frase de Karl Marx: "Todos los grandes hechos de la historia universal se repiten dos veces. Una vez como tragedia y la otra como parodia," Kartún satiriza, en versos gauchescos, una costumbre de la clase opulenta argentina de principios del siglo XX. En la bodega de un transatlántico que viaja rumbo a Europa, se desarrolla un triángulo formado por el Niño Argentino (de la clase alta), el peón que ordeña a diario la vaca para surtir de leche fresca a la familia del Niño, y la vaca misma, que será sacrificada al llegar a su destino. La obra, con la magistral actuación de Mike Amigorena como El Niño, es una gran payada que rebosa de humor y lucidez, con ecos de la picardía de Anastasio el Pollo de Santos Vega y del cinismo del Viejo Vizcacha, de José Hernández; pero al mismo tiempo revela las profundas ambigüedades y las continuas diferencias de clase, cultura, lenguaje y carácter que distingue a unos argentinos de otros.

El título de la obra concebida por Eva Halac con adaptación teatral de Adrián Blanco: Español para extranjero (Sala Caras y Caretas), puede resultar confuso al espectador, ya que insinúa más a una lengua - el español - que a una nación - la argentina - subjuygada por otras, en este caso la española y la francesa. El Virrey Liniers, su protagonista, es un francés al servicio de la corona española de Fernando VII, quien luego de haber vencido a los invasores ingleses, revela su falta de lealtad hacia la patria que gobierna, y se manifiesta, aunque conflictuadamente, en favor de los españoles. Eva Halac dirige la pieza con el dramatismo propio de una ópera lírica, tanto en su selección musical de valses y minuets, como en la poesía de salón que los personajes recitan, como en su vestuario suntuoso, como en la muestra dramática de efectos sonoros y escénicos que engalanan el escenario.

La adaptación de una novela de Leopoldo Marechal Megafón o la guerra (Sala Centro de Cooperación) propone una meta exitosamente realizable en una novela extensa, propia de los años cincuenta en América Latina. La reducción de la novela en tiempo y en espacio, a una obra teatral, si bien conserva el ímpetu exaltado, vocalizado por un elenco numeroso, resulta demasiado ambiciosa y no logra transmitir la intención desbordante del autor, de dramatizar una epopeya popular, que cubre huelgas obreras, luchas de clases, mujeres idealizadas y ultrajadas, hombres demagógicos y rufianes insaciables. 


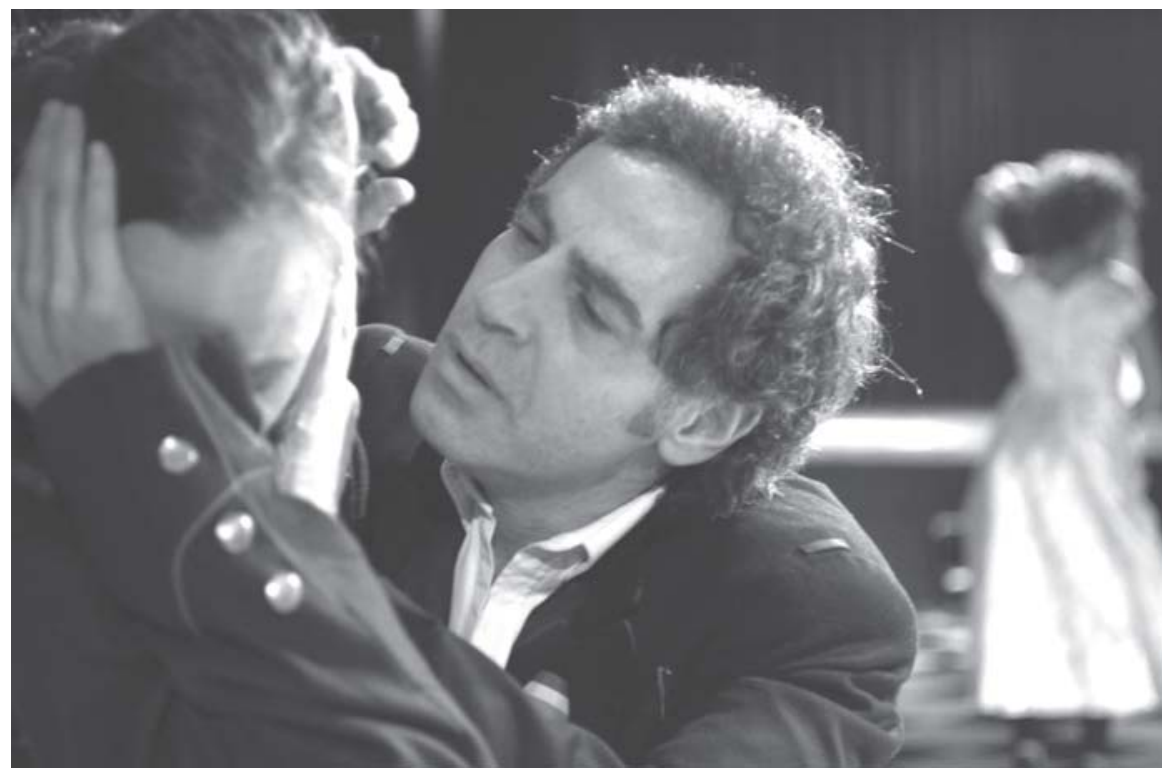

Español para extranjeros. Foto de: Guillermo Monteleone.

Cabe agregar que a los espectáculos argentinos, a los cuales se añaden las numerosas funciones de tango en todas sus variedades, se suma un gran número de obras norteamericanas y europeas, y actividades teatrales del festivales, como el IV Festival Internacional de Buenos Aires, que convoca funciones de danza, artes visuales, música y teatro universal. Conjuntamente con los talleres de teatro, anunciados en los diarios de la ciudad, se incluyen representaciones profesionales, aunque sin escenografía, como las del XVI Congreso Internacional de Teatro Iberoamericano y Argentino, organizado por GETEA del 7 al 11 de agosto, en el que participan actores y directores como Eduardo Pavlovsky con Potestad, (bajo la direccion de Norman Briski), Psicosis 4:48 de Sara Kane, interpretado por Leonor Manso, y un espectáculo unipersonal a cargo de Ana María Bovo, amén de numerosas mesas redondas, entrevistas y diálogos con actores, dramaturgos, teatristas y críticos de teatro.

Imposible abarcar cuanto una quisiera durante dos semanas en Buenos Aires. Queda, sí, el gusto por ver más, la satisfacción de un saludable, aunque breve empacho, y la necesidad de frenarse para apreciar a distancia - desde Nueva York - el panorama tan rico, en calidad e intensidad, como el que ofrece la escena porteña durante este mes de agosto.

Queens College, CUNY 